\title{
David M. Dines, Joshua S. Dines, T. Bradley Edwards (eds): Reverse shoulder arthroplasty: a practical approach
}

\section{Thieme Verlag, New York, Stuttgart, Delhi, Rio de Janeiro, 2017, 256 pp, num. figs., 280.0 mm, Hardcover (GEB) + plus e-content, EUR (D) 139,99 EUR (A) 144,40 CHF 161,00, ISBN: 978-1- 62623-360-7}

\section{Pierre Kehr ${ }^{1}$}

Received: 6 May 2018 / Accepted: 20 May 2018 / Published online: 4 June 2018

(c) Springer-Verlag France SAS, part of Springer Nature 2018

This international collective work, with North American majority, but with European authors and in particular French, covers in 29 chapters the issue of the reverse shoulder prosthesis. The book starts with a detailed history in which the French reader will with pleasure find work of our regretted Paul Grammont.

After a recall of basic, the various surgical techniques are then exposed, with many diagrams and operational figures. The results are analyzed as well as the complications and the means of curing the failures.
This work is very complete, which answers the questions that one can be asked on the arthroplasty of this complex joint.

To advise as well with the specialists in the subject as with the rehabilitation doctors whose role is essential for obtaining a good performance.

\section{Compliance with ethical standard}

Conflict of interest The author declares that he has no conflict of interest. 